\title{
Papaverine is a confounding factor in neurological assessment after cerebral aneurysm clipping: Report of three cases and review of the literature
}

\author{
Veena Sheshadri, Rohini Surve, BA Chandramouli ${ }^{1}$
}

\begin{abstract}
Intracisternal papaverine instillation is being used across many centers after cerebral aneurysm clipping to prevent and treat cerebral vasospasm. Pupillary dilatation secondary to papaverine can interfere with the neurological assessment postoperatively. This report describes pupillary changes in three patients following the papaverine application after craniotomy and aneurysm clipping, with one patient developing contralateral pupillary dilatation and the other two having bilateral pupillary dilatation. The pupillary changes resolved over $30 \mathrm{~min}$ to $4 \mathrm{~h}$ postoperatively. We conclude that pupillary changes following papaverine instillation could be a transient phenomenon and should not be considered ominous in absence of new onset neurological deficits. Intraoperative somatosensory evoked potential monitoring also helped in postoperative decision making in all our cases.
\end{abstract}

Key words: Aneurysm clipping, intracisternal papaverine, pupillary dilatation and areflexia

\section{INTRODUCTION}

Papaverine, a smooth muscle relaxant and potent cerebral vasodilator ${ }^{[1]}$ is instilled intracisternally in many centers after cerebral aneurysm clipping to prevent and treat cerebral vasospasm. There are reports of ipsilateral, contralateral and even bilateral dilatation of pupils after intracisternal application of papaverine following aneurysm surgeries..$^{[2-5]}$ Pupillary dilatation can be a significant confounding factor in the assessment of neurological status immediately after cerebral aneurysm clipping.

The present report is of three patients undergoing craniotomy and aneurysm clipping, with pupillary dilatation secondary to intracisternal instillation of papaverine. Cortical somatosensory evoked potentials

\begin{tabular}{|l|l|}
\hline \multicolumn{2}{|c|}{ Access this article online } \\
\hline Quick Response Code: & Website: \\
\hline & www.jnaccjournal.org \\
\cline { 1 - 2 } & \\
\hline
\end{tabular}

(SSEPs) monitoring was also done intraoperatively in all the patients.

\section{CASE REPORTS}

\section{Case 1}

A 43-year-old female presented with a history of seizure and two episodes of vomiting a week prior, followed by intermittent headache since then. On admission, World Federation of Neurological Surgeons (WFNS) grade was I and Hunt and Hess grade was I. Computed tomography (CT) angiogram showed left middle cerebral artery (MCA) bifurcation aneurysm. The patient was positioned supine with $30^{\circ}$ rotation of the head to the right side. Anaesthesia was induced with injection fentanyl $(2 \mathrm{mcg} / \mathrm{kg})$, propofol $(2 \mathrm{mg} /$ $\mathrm{kg})$ and rocuronium $(1 \mathrm{mg} / \mathrm{kg})$ and maintenance was with total intravenous anaesthetics (injection fentanyl and propofol infusions). Intraoperative monitoring included invasive haemodynamic monitoring along with SSEP monitoring (median nerve stimulation, CP3-CP4 recording channel). Surgical aneurysm clipping was uneventful. Before dural closure, 10 cc of $0.6 \%$ papaverine was instilled intracisternally. At extubation, contralateral pupil was dilated and not reacting to light

Departments of Neuroanaesthesia and ${ }^{1}$ Neurosurgery, Vikram Hospitals, Bengaluru, Karnataka, India

Address for correspondence:

Dr. Veena Sheshadri, 58, $4^{\text {th }}$ Cross, LIC Colony, Jayanagar 3 3r Block (East), Bengaluru - 560 041, Karnataka, India. E-mail: drveena_4u@yahoo.co.in 
but ipsilateral pupil reactivity was normal. However, since the patient was conscious without neurological deficits, trachea was extubated. Pupil normalised after $1 \mathrm{~h}$. She was discharged home after 4 days.

\section{Case 2}

A 67-year-old male presented with severe headache for 3 days. WFNS grade was I and Hunt and Hess grade II. CT angiogram showed right MCA bifurcation aneurysm. Anaesthesia and surgical aneurysm clipping were uneventful. Undiluted papaverine (2cc of $3 \%$ ) was applied intracisternally before dural closure without haemodynamic changes. After neuromuscular blockade reversal, patient's Glasgow coma scale was E1M5VT with left hemiparesis and pupils bilaterally dilated and nonreactive to light. Immediate CT scan revealed no significant changes. Ipsilateral pupil normalized at $30 \mathrm{~min}$. After $1 \mathrm{~h}$, both pupils had normalized, hemiparesis improved and trachea was extubated since the patient became alert without deficits. He was discharged after 4 days.

\section{Case 3}

A 33-year-old male was admitted with a history of headache and vomiting of 4 days duration. WFNS grade was IV and Hunt and Hess grade IV. CT angiogram showed left MCA bifurcation aneurysm. After permanent clipping, papaverine $10 \mathrm{cc}$ of $0.6 \%$ was instilled. On completion of the procedure, pupils were bilaterally dilated and nonreactive to light. Ipsilateral pupil reverted to normal in $30 \mathrm{~min}$, and contralateral took $4 \mathrm{~h}$. Patient was extubated after $6 \mathrm{~h}$ and discharged on day 10.

Bilateral SSEPs recorded during all the cases were normal throughout the procedure

\section{DISCUSSION}

Papaverine is a benzylisoquinoline alkaloid found in opium. It relaxes smooth muscles, especially when they are spasmodically contracted. Action is by specific inhibition of cyclic adenosine and guanosine monophosphate phosphodiesterases.$^{[6]}$ Neurosurgeons have been using topical papaverine for reversal of vasospasm since the time it was advocated by Pool. ${ }^{[7]}$ Transient pupillary changes with intracisternal papaverine are documented in the literature as also other complications like facial and auditory nerve palsies, haemodynamic changes, cardiac arrest, malignant hyperthermia and metabolic acidosis..$^{[2]}$

Literature reports mention causes of postoperative unilateral or bilateral mydriasis as those due to drugs such as anticholinergics, tramadol, haloperidol, topical nasal or ocular phenylephrine, nebulized ipratropium, midbrain tumours and causes of brainstem displacement such as operative trauma, haematoma and pneumocephalus, ophthalmoplegias, compression or trauma to eyeball, adhesions and tearing of iris, displacement of implanted intraocular lenses.

Pupils were equal and normally reacting in all three patients preoperatively and changes occurred after uneventful craniotomy. First patient had contralateral mydriasis, and the other two had bilateral pupillary dilatation with the contralateral pupil remaining dilated longer than the ipsilateral during resolution of changes. The time to normalisation ranged from $30 \mathrm{~min}$ to $4 \mathrm{~h}$. All cases had pupillary nonreactivity to light (areflexia) and normal extraocular movements.

Chittiboina et al. showed ipsilateral oculomotor palsy in three patients following 3-5 cc of 3\% topical papaverine resolving over a 3-24 $\mathrm{h}$ period. ${ }^{[2]}$

Pritz has reported ipsilateral fixed and dilated pupils in three patients, lasting 2-4 h after craniotomy and supratentorial aneurysm clipping in which the oculomotor nerve was not manipulated. He related this phenomenon to intracisternal papaverine injection (3 cc of $2 \%$ solution). ${ }^{[3]}$ Another report by Pritz describes contralateral pupillary dilatation after intracisternal papaverine ( 20 cc of $1.5 \%)$ irrigation. He attributed this to $80^{\circ}$ head rotation and papaverine reaching the dependent contralateral cisterns. ${ }^{[4]}$

Bala et al. have reported bilateral mydriasis and areflexia after uncomplicated craniotomy for anterior communicating artery aneurysm clipping where intracisternal papaverine (10cc of $0.6 \%$ ) was used. ${ }^{[5]}$ They hypothesised that papaverine, being a weak local anaesthetic, blocks the superficial parasympathetic pupillomotor fibers of the oculomotor nerve after it exits the brainstem. They attributed the bilateral dilatation to free communication between various cisterns and patient head tilt of $30^{\circ}$ facilitating the flow of papaverine to opposite side.

In concurrence with the few literature reports available, we attribute the mydriasis and pupillary areflexia in our cases to intracisternal papaverine instillation. Interestingly, the pupillary dilatation occurred irrespective of papaverine dilution, unlike the findings of Chittiboina et al. Though the exact mechanism remains unknown, the most plausible explanation would be that given by Bala et al. When only superficial oculomotor fibers are blocked and deeper fibers not affected, the normal extraocular movements are preserved without ptosis. Head rotation to facilitate surgical access along with liberal intercisternal communication may have led to papaverine gravitating to the dependent contralateral cisterns and causing prolonged contralateral pupillary dilatation and delayed normalisation. Hendrix et al. 


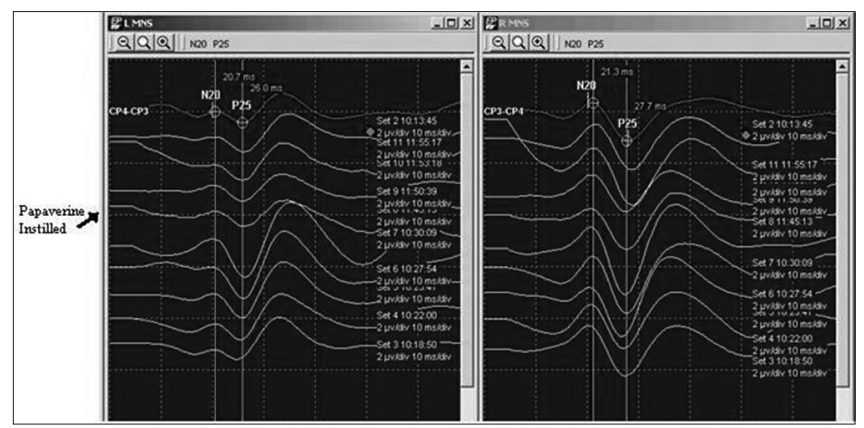

Figure 1: Intraoperative recordings showing bilateral cortical responses to median nerve stimulation (Case 2)

in a study on intra-arterial papaverine discussed that pupillary drug testing with pilocarpine would be expected to cause rapid constriction in case of oculomotor dysfunction or ganglionic blockade. ${ }^{[8,9]}$ This finding merits further study in the context of pupillary changes due to the intracisternal papaverine application.

Moran et al. reported transient brainstem dysfunction as shown by depressed median and tibial nerve SSEPs in three patients after a topical papaverine $1 \%$. They concluded that though papaverine readily penetrates neural tissues, the mechanism of any brainstem effects remains undetermined. ${ }^{[10]}$ The absence of SSEP changes [Figure 1] in all our cases ruled out the possibility of brainstem dysfunction.

Based on our center's experience of three cases of pupillary changes with intracisternal papaverine, we conclude that this could be a transient phenomenon and should not be considered ominous if the surgery has been uneventful. In patients with normal neurological assessment, immediate postoperative CT scan may be considered only in case of persistent pupillary changes and new onset neurological deficits. Intraoperative neurophysiological monitoring in the form of SSEP will supplement the postoperative assessment. Multicenter studies are required to determine the frequency and duration of pupillary changes with intracisternal papaverine and relationship with the dilution of papaverine.

\section{REFERENCES}

1. Ogata M, Marshall BM, Lougheed WM. Observations on the effects of intrathecal papaverine in experimental vasospasm. J Neurosurg 1973;38:20-5.

2. Chittiboina P, Willet O, Nanda A, Guthikonda B. Transient oculomotor nerve palsy after topical administration of intracisternal papaverine.Acta Neurochir(Wien) 2011;153:431-3.

3. Pritz MB. Pupillary changes after intracisternal injection of papaverine. Surg Neurol 1994;41:281-2.

4. Pritz MB. Contralateral pupillary dilatation after intracisternal papaverine instillation. Surg Neurol 2007;67:546.

5. Bala I, Ghai B, Kumar A, Pratap M. Bilateral pupillary dilatation after intracisternal papaverine application. Anesth Analg 2006; 102:965.

6. Siuciak JA, Chapin DS, Harms JF, Lebel LA, McCarthy SA, Chambers $\mathrm{L}$, et al. Inhibition of the striatum-enriched phosphodiesterase PDE10A: A novel approach to the treatment of psychosis. Neuropharmacology 2006;51:386-96.

7. Pool JL. Cerebral vasospasm. N Engl J Med 1958;259:1259-64.

8. Hendrix LE, Dion JE, Jensen ME, Phillips CD, Newman SA. Papaverine-induced mydriasis. AJNR Am J Neuroradiol 1994; 15:716-8.

9. Plum F, Posner JB. Diagnosis of Stupor and Coma. $4^{\text {th }}$ ed. New York: Oxford University Press Inc.; 2007. p. 54-9.

10. Moran CM, Mahla ME, Reichwage B, Lewis S, Peters K, Seubert CN. Transient bilateral brainstem dysfunction caused by topical administration of papaverine. J Neurosurg 2011; [Epub ahead of print].

How to cite this article: Sheshadri V, Surve R, Chandramouli B. Papaverine is a confounding factor in neurological assessment after cerebral aneurysm clipping: Report of three cases and review of the literature. J Neuroanaesthesiol Crit Care 2016;3:40-2.

Source of Support: Nil, Conflict of Interest: None declared. 